\title{
Chain Action - How Do Countries Add Value Through Digital Government?
}

\author{
Jaromir Durkiewicz \\ Department of Informatics in Management \\ Gdańsk University of Technology, Poland \\ jaromir.durkiewicz@pg.edu.pl
}

\author{
Tomasz Janowski \\ Department of Informatics in Management \\ Gdańsk University of Technology, Poland \\ Department for E-Governance and Administration \\ Danube University Krems, Austria \\ tomasz.janowski@pg.edu.pl
}

\begin{abstract}
This study examines how countries develop and benefit from Digital Government (DG). The literature proposes various conceptualizations of the valueadding logic of $D G$, but the benchmarking practice is not responding to such proposals. For instance, the United Nations' E-Government Survey combines the readiness and uptake indicators and fails to cover any impact indicators; thus, its diagnostic value is limited. To overcome this limitation, we introduce a new assessment scheme based on the DG value chain concept and pursue the question: how do the world countries add value in this chain? Reassembling the UN's e-Government Survey indicators and the World Bank's Worldwide Governance Indicators, we examine how the 191 UN Member States converted their readiness into uptake and uptake into impact over the 2014-2018 period. The results rank the countries concerning their performance along the $D G$ value chain, identify hotspots, and calculate the value chain performance of regional and economic groups.
\end{abstract}

\section{Introduction}

An infamous psychometric bon mot, inspired by [1], suggests that intelligence is what the tests of intelligence measure. Regardless of how accurate this statement is, a person scoring high in the IQ tests is usually considered intelligent. Can the quality of countries' Digital Government (DG) be assessed in the same way? Do high DG benchmark scores indicate high DG quality? Some state that DG is an umbrella concept, which means "many different things to different people according to one's focus" [2, p. 186]. Thus measuring DG is about subscribing to a particular framework and adopting its success criteria, not unlike a tacit acceptance of an IQ test.

However, we think that the point lies elsewhere. The literature puts DG at the center of a process aiming to create public value [3], including numerous value chain models, e.g., [4]. In their simplest generic form, such models identify the stages of readiness, uptake, and impact, although the terminology used could vary. The issue is whether sufficient value is added via transitions between consecutive stages of a country's DG value chain. Further investigation of this issue leads to diagnostic questions whether this country succeeds in building and using its DG given its state of readiness, whether the usage of DG brings actual benefits to the country, and a practical issue of how to calculate answers to both questions.

The UN E-Government Survey is arguably the most recognizable, global, and long-lasting Survey dedicated to assessing country-level DG. The Survey supplies two indices - E-Government Development Index (EGDI) and E-Participation Index (EPI), which triggered numerous academic studies and political debates. Adding to these debates, we note that both indices skip the logic of value addition through the DG value chain: EGDI combines the readiness and uptake indicators, and both indices fail to consider any impact indicators. Thus we must agree with the following observation: "little attention has been given to the way in which the effects of Digital Government policies or initiatives can create public value to solve societal problems" [5, p. 29]. Even worse - the results may be misinterpreted or misused. According to [6, p. 171], "it is always necessary to be aware of the risks of their [benchmarks'] politicization. Decision-makers can be influenced by perceptions, so it is important to ensure that those perceptions are correct". From a diagnostic perspective, the Survey leaves two key questions unanswered. Is DG uptake commensurable with DG readiness? Does it generate enough DG impact?

To address such questions, we constructed a new assessment model to capture the DG value chain's logic. For simplicity, the model consists of three stages - readiness (R), uptake (U), and impact (I); and two transitions (activities) - readiness-to-uptake (R2U) and uptake-to-impact (U2I). Seeking a balance between capturing a country's DG value chain (relevance) and 
data availability to capture this chain (feasibility), we realized that existing benchmarks, while not delivering sufficient diagnostic value on their own, could still provide data for the new model. With this in mind, we decided to represent the readiness stage by two EGDI components - Telecommunication Infrastructure Index (TII) and Human Capital Index (HCI), and the uptake stage by the third EGDI component - Online Service Index (OSI), together with EPI. We also decided to represent the impact stage, which is missing from the UN Survey, by three components of the World Bank's Worldwide Governance Indicators [7]: Government Effectiveness (GE), Voice and Accountability (VA), and Control of Corruption (CC). Technically, multiple indices at each stage were joined into a single synthetic value $\mathrm{R}, \mathrm{U}$, and $\mathrm{I}$, employing the standard statistical technique of Principle Component Analysis.

The primary diagnostic outcome of this approach is the values of the R2U and U2I indicators, calculated by subtracting the values of $U$ and $R$ and the values of $I$ and $\mathrm{U}$, respectively. Concerning the years of capture, assuming a period between stages and in line with the UN and World Bank's surveys' availability, we took the value of R at 2014, U at 2016, and I at 2018. The population consists of $191 \mathrm{UN}$ member states. Analyzing this data permitted ranking countries concerning their performance along the DG value chain, identifying hotspots, and calculating average performances of the regional and economic groupings.

The approach proposed in this study may open up new diagnostic possibilities for DG evaluation and benchmarking. They include: quantifying countries' progress along their DG value chain, verifying the evidence of digital performance against government propaganda claims, and supporting the analysis of the mechanisms behind global digital transformation. The results may help identify cases of countries and groups that merit closer examination concerning their progress along the DG value chain, including causes of their under-performance or over-performance. They could also help verify the reliability and informational value of existing instruments. The target audience includes policy-makers, public managers, analysts, researchers.

The rest of this paper is structured as follows. Section 2 carries out a literature review to serve as a background for this study. Section 3 presents the main research problem, along with the DG value chain assessment framework, as well as the data and methods used to address this problem. Section 4 applies this framework to the collected data and describes the findings. Section 5 carries out a discussion on the process and findings. Section 6 summarizes the main findings, outlines the limitations of this research, and provides future research directions.

\section{Background}

This section carries out a literature review to build the background for this study. We discuss the process logic (Section 2.1), three perspectives on DG as an outcome of a process (Section 2.2), as a process itself (Section 2.3) and as a value chain (Section 2.4), and the measurement of the DG value chain in general (Section 2.5) and with the UN Survey (Section 2.6).

\subsection{Process logic}

Defining a process as "a series of actions to achieve a result" or "a series of changes that happen naturally" [8] puts DG in the context of a process right at its definition. Considering a compilation of existing DG definitions [9], it can be easily noticed that besides the Information and Communication Technology (ICT) component, most definitions follow the general logic of ICT-driven transformation. The expressions such as "to benefit citizens", "to enable and improve efficiency" or "in the transformation of government" [9, p. 8] indicate that we expect changes to happen through some action. A similar observation applies to other compilations of this type, e.g. [10, p. 972].

It should be noted that the literature introduces several DG-related terms that follow the process orientation. First, the term "e-governance" refers to the use of ICT "to enhance the governance process and support e-Democracy, e-Government, and e-Business" [11, p. 385] or represents a "grid of governmental and technological relations" for "a political plan, a vision, or an institutional glue" [12, p. 39]. This term is also explored in [13] to conclude that "each author or scholar has to set out his or her definition first and proceed from there" [13, p. 8]. Another term is "transformational government" [14][15], understood as "reengineering and e-enabling back-office processes and information systems to facilitate more joined-up and citizen-centric e-government services" $[15$, p. 1]. While the terminology used is rich, we subsequently confine to the term Digital Government (DG).

How can DG be adapted to the process logic? Two variants stand out in reply: whether DG is considered an outcome of a process or a process itself.

\subsection{DG as an outcome}

The first variant is principally about DG that evolves. At the start of this evolution is readiness, generally understood as the government's capacity and willingness to adopt ICT solutions [16]. The construct constituted the foundation of EGDI and remained its focus until 2008 [17], with changes in readiness 
illustrating the process of DG development. Readiness is a subject of criticism from theoretical and practical (assessment-oriented) standpoints [16][18].

Deeper understanding involves stage-based models, designed to "better understand the current situation of digital government in terms of results" [19, p. 408]. The focus is on the technical, functional, and political growth, referring to DG as a whole or its components, such as Internet portals. The process can lead from "cultivation" to "revolution", from (Web) "presence" to "political participation", from "online presence" to "digital democracy", etc. [20].

This process can also be labeled "evolution", as in [21], which draws a four-stage path from "digitization" as the primary technology stage to "contextualization" as the advanced policy stage. The terms used by the authors are somewhat confusing, e.g., transformation is one of the stages in the evolution model [21]. Other authors, e.g., [5, p. 18] apply this term to denote change, modernization, and innovation. Yet, others speak of growth or development [22].

Regardless of the terminology used, the models above describe the process of DG development and use. Whether this process satisfies the first definition a series of actions to achieve a result, or the second - a series of spontaneous changes, is a philosophical issue: to what extent the transformation can be designed, scheduled, and executed, and whether technological disruption can take control over this transformation.

\subsection{DG as a process}

The second variant is closer to the idea of this study. Here, the DG itself is like a business process, a collection of activities that produce specific outputs [23, p. 366]. Within this setting, one can ask: what are the activities, and what are the outputs?

While DG should be developed and used as part of a process, this DG uptake is neither the starting point nor the output in itself. In line with the readiness construct, DG uptake requires favorable conditions on the ground - social, economic, technical, political. Concerning outputs, they logically entail the impact that DG is intended to create. We can then speak of at least two activities: turning DG conditions into DG uptake and turning DG uptake into DG impact.

Management studies offer various templates for such models. Besides a business process, the most generic one is a logic model, i.e., "a roadmap or simplified picture that displays connections between resources, activities, and outcomes", in its simplest form just linking inputs, outputs, and outcomes [24]. Here DG uptake would refer to a logic model's output, and its external effects would be labeled as outcomes.
Another example is the value chain [25], which can be "a powerful tool in diagnosing and explaining how the management of competitive advantage takes place within the firm" [26, p. 3]. In its original business context, the concept is built around such constructs as value (price), primary activities (e.g., logistics), and supporting activities (e.g., procurement) [25][26]. The universal feature of the value chain is value enhancement: "The activities that a firm performs become part of the value added produced from a raw material to its ultimate consumption" [26, p. 1].

What should be taken as a value to enhance? The choice may be easy for businesses but less evident for DG. Generically, it can be public value, though this construct is "so fundamental as to be unmanageable" [27, p. 355]. The arguments for such a choice follow "Public value creation has become the expectation that digital government initiatives have to fulfill" $[3, \mathrm{p} .1]$ or "Public value is intended to be the equivalent for the public sector of private value" [4, p. 277]. The concept of DG as a public value booster has taken a steady position within the research domain [28]. In the sequel, we elaborate on the logic of this enhancement.

\subsection{DG as a value chain}

The literature offers several DG-related value chain models, though different motivations and inconsistent terminologies make the landscape far from coherent.

Heeks proposes a comprehensive conceptualization of the DG value chain, organized into precursors, strategy, inputs, development, intermediates, adoption, use, outputs, impacts, and outcomes [4]. They form the "higher-order stages" of readiness, availability, uptake, and impact, also indicated in [29]. This model can be compared to an early elaboration [30], which proposes a more business-oriented chain. Heeks is also engaged in the construction of the ICT for Development (ICT4D) project framework [31], based on the value chain structurally similar to the one discussed above, although with outcomes preceding impacts [31, p. 3]. A slightly simpler variant is proposed in [32], treating hope as the primary input and incentive.

Although not labeled as a value chain explicitly, an interesting model is introduced in [33]. The model captures the transformation logic, from transformation reasons, objects, and processes, to outputs, outcomes, and impacts. Value creation is among the identified impacts in this model [33, p. 9].

Despite all terminological and conceptual diversity, for simplicity, we now associate this kind of general process logic with a DG value chain. 


\subsection{Measuring DG value chain}

Most of the models above provide a comprehensive explanation of the value creation through DG, but to transfer them to the realm of practical measurement, assessment, and benchmarking is still an open problem. In that sense, theory overtakes practice.

While [4] provides an extensive set of suggestions on how to refer to the structure of the chain in the design of new benchmarks, it also indicates challenges: "benchmarking tends to focus on the core of the value chain - intermediates, adoption, and use - rather than the main upstream (precursors, inputs) or downstream (impacts, outcomes, to some degree outputs) elements" and benchmarking is limited in "understanding the value of e-Government" [4, p. 267].

A similar problem is identified in [5]: "suitable evaluation indicators for the assessment of the success of Digital Government policies and initiatives are lacking" and "little attention has been given to the way in which the effects of Digital Government policies or initiatives can create public value to solve societal problems" [5, p. 29]. Deducting from [29], while early stages of the value chain are relatively well-covered by the global or country-level benchmarks, local and transient benchmarks mostly dominate later stages.

A different reflection can be found in [6]. Although the author supplies a list of potential elements to be measured, corresponding to the chain logic, e.g., inputs, outputs, effectiveness, and impacts, he also states that "Benchmarks should ... be targeted to answer specific and narrow questions" [6, p. 171].

Even if there were widely available benchmarks that precisely capture each stage performance, they would say little on their own about the state of the chain as a logical sequence of value-creating steps. Given this, some studies confront digital assessment with external measures, examining how DG affects, e.g., corruption [34] or effectiveness [35], or how DG quality is predetermined by the type of political regime [36]. However, such efforts are oriented towards exploring the characteristics of DG itself without focusing on the performance of individual countries.

Some studies also apply a more holistic approach, such as: balancing a country's DG performance with its expected governance impact [37] - one of few globally scoped studies; monitoring the whole DG system in Belgium [38]; or monitoring and measuring "the public value of ICT interventions" in Italy [39].

\subsection{Measuring DG value chain with EGDI}

Designing and implementing a comprehensive DG benchmark is a massive technical and organizational endeavor. Thus, when speaking of globally-scoped country-level DG benchmarks, academics and analysts are left with few instruments [40, p. 387][41, pp. 4-5]. Among them, EGDI and EPI supplied within the UN's E-Government Survey [17] cover the broadest scope in terms of geographic coverage (193 countries in 2018) and regularity (biennial editions from 2003 to 2020).

However, these most recognizable indices are also intensively criticized [42, p. 68]; a compilation of the critique would fill a paper by itself. For this study, we should note that the technical construction of the index [17, pp. 199-200] leads to a mixture of measures that refer to different stages of the DG value chain. Mukamurenzi et al. notice that "EGDI mixes egovernment development with general development in a way that on the one hand is reasonable as both technical infrastructure and literacy are prerequisites for use of e-government services, on the other hand, makes it difficult to discern the e-government component in development" [43, p. 127], while according to [44, p. 69], "since HCI is a component of EGDI, this component may artificially make EGDI to have higher value than the reality".

The problems with EGDI can also be explained through the theory of measurement, which offers two basic measurement models [45, p. 103]. In the reflective model, individual indicators reflect an underlying construct, e.g., the DG value chain. In the formative model, the construct's meaning is determined by selecting particular indicators [45].

EGDI is based on the formative model. Even the Survey's designers are not exactly convinced what this composite measure is meant to illustrate [17] readiness, maturity, development? The framework also remains technically much the same from the beginning, even though its authors declare updating it "to reflect new trends in e-government" [17, p. xx].

Consequently, the relevance of the conclusions built solely upon the results of the existing benchmarks is moot. Numerous studies suggest keeping distance from these values, which do not guarantee reliable diagnostic insights, even if nominally correct. For example, there are significant dissonances between DG scores and the quality of real governance [37]: "any country, no matter how undemocratic, can score high on eParticipation" [46, p. 32]; or "autocracies do not perform worse in later UN editions" [36, p. 276].

Reliable DG evaluation is key to countries that devote public funds to developing and promoting their DG and its use. According to [5, p. 29], "measuring and evaluating effects of digital government initiatives $\ldots$ is of great strategic importance for any public sector organization". Referring to the value chain to carry out reflective measurement of the DG process may help separate useful insights from politically-inspired or technologically-driven information noise. 


\section{Methodology}

This section presents a research approach adopted to address the central research problem: how do the world countries add value through the DG value chain? To answer this question, we had to consider existing theoretical models for value creation and the scarcity of international instruments to measure such value creation. Hence, we designed a custom conceptual model to balance what is and what should be.

In the rest of this section, we present the DG value chain's conceptual model in Section 3.1, gathering and processing data to populate this model in Sections 3.2 and 3.3 respectively, the validity of the model in Section 3.4, and research questions in Section 3.5.

\subsection{Conceptual model}

Before constructing the model, we adopted some conceptual and technical assumptions. First, to focus on the value changes along the DG value chain rather than on the values produced at different stages of the chain. Second, as value creation takes time, to examine value changes within a period. Third, to base the model on the UN Survey as the most recognizable and steady DG benchmarking project. Fourth, to relate DG's impact with improvements in public governance, arguably associated with many benefits of DG.

Due to the level of abstraction and the complexity of interactions, quantifying and measuring the value chain is nontrivial. Certain propositions emerge [47][48], often tied to a sectoral context. Also, there is no single model for the DG value chain. While a path from readiness to impact is repetitive, different terms and explanations emerge at implementation. Given the central position of DG development and use (uptake) and the assumption that there should be at least one stage preceding and one following DG uptake, we propose a simplified model as a compromise between the logic of the DG value creation and the offer of global benchmarks. Its stages are described in Table 1.

Table 1. Stages of the DG value chain model [4]

\begin{tabular}{|l|l|}
\hline Stage & Description \\
\hline Readiness (R) & $\begin{array}{l}\text { Fundamental preconditions of DG, } \\
\text { associated with precursors or inputs }\end{array}$ \\
\hline Uptake (U) & $\begin{array}{l}\text { Mechanisms and use of DG, corresponding } \\
\text { to intermediates or outputs }\end{array}$ \\
\hline Impact (I) & $\begin{array}{l}\text { Governance benefits supported by DG, } \\
\text { corresponding to impacts and outcomes }\end{array}$ \\
\hline
\end{tabular}

Most DG value chain conceptualizations only refer to the concept of stages, e.g., development is one of the stages in $[4$, p. 269]. However, as commented earlier, capturing a country's state of DG in concrete stages without referring to the state of DG in other stages says nothing about the value created by DG. The latter is about relationships between stages. The clue of our approach is to examine the transitions in the DG value chain, not the stages of this chain. In other words, to estimate the scale of value addition, we focus on the differences between stages. To this end, we define two transitions between consecutive stages, as in Table 2: $\mathrm{R} 2 \mathrm{U}$ between and $\mathrm{R}$ and $\mathrm{U}$ and $\mathrm{U} 2 \mathrm{I}$ between $\mathrm{U}$ and $\mathrm{I}$.

Table 2. Transitions in the DG value chain model

\begin{tabular}{|l|l|}
\hline Transition & Description \\
\hline R2U & Turning DG readiness into DG uptake \\
\hline U2I & Turning DG uptake into DG impact \\
\hline
\end{tabular}

\subsection{Data}

To calculate the values of the $\mathrm{R}$ and $\mathrm{U}$ stages in the DG value chain of a country, we use the UN Survey's constituent indicators. To calculate R, we apply the Telecommunication Infrastructure Index (TII) and the Human Capital Index (HCI) that represent the country's digital infrastructure and human capacity. To calculate U, we use the Online Service Index (OSI) that represents online public services and the eParticipation Index (EPI) that describes interactions between government and citizens in this country [17].

As the I stage is not captured by any of the UN Survey's indicators, we refer to three World Bank's Worldwide Governance Indicators instead [7] Government Effectiveness, Voice and Accountability, and Control of Corruption. We associate them with those aspects of governance that are expected to benefit from digitalization, regarding both the normative standpoints, e.g. [9], and the major trends in the analytical studies, e.g. [34][35][49].

As the literature does not define how much time a single value addition takes, we took the span between two consecutive editions of the UN Survey - two years - as our time unit. Thus the latest $\mathrm{R}$ data comes from 2014, U from 2016, and I from 2018. The objects under examination were all UN member states represented in the Survey. However, we eliminated Monaco and San Marino, for which some values of the WGI indicators were missing, retaining 191 countries.

To consider the DG value chain performance of groups of countries, not only individual ones, and thus capture possible macro-trends, we included some data external to the DG value chain. Such data includes REGION - geographical context and the countries' regional assignments [50], and INCOME - economic context and the countries' income group assignment [51]. For further comparison, we also reached to the original values of EGDI. All three variables were taken in the middle year -2016 . The variables are in Table 3. 
Table 3. Original indicators used in the research

\begin{tabular}{|c|c|c|c|}
\hline Stage & Measure & Scale & Source \\
\hline \multirow{2}{*}{$\mathrm{R}$} & Human Capital Index (HCI) & \multirow{2}{*}{0 to 1} & \multirow{2}{*}{ [52] } \\
\hline & Telecom Infrastructure Index (TII) & & \\
\hline \multirow{2}{*}{$\mathrm{U}$} & Online Service Index (OSI) & \multirow{2}{*}{0 to 1} & \multirow{2}{*}{ [52] } \\
\hline & E-Participation Index (EPI) & & \\
\hline \multirow{3}{*}{ I } & Government Effectiveness (GE) & \multirow{3}{*}{ z-score $(0,1)$} & \multirow{3}{*}{ [53] } \\
\hline & Voice and Accountability (VA) & & \\
\hline & Control of Corruption (CC) & & \\
\hline & Region (REGION) & 17 regions & [50] \\
\hline & Income group (INCOME) & 4 levels & [51] \\
\hline & E-Gov. Development Index (EGDI) & 0 to 1 & [52] \\
\hline
\end{tabular}

\subsection{Data processing}

Data processing involves replacing constituent indicators like, e.g., HCI and TII with the single one $\mathrm{R}$ representing a stage in the DG value chain. As a stage is a well-defined construct within a chain, we expected high correlations between the indicators at each stage. As the model is reflective, we also hope that a different but still relevant to the central concept set of indicators would also support the underlying constructs and reveal relatively high correlations.

To calculate three synthetic indicators for $\mathrm{R}, \mathrm{U}$, and I, each quantifying different stages of the chain in a year, we applied the Principal Component Analysis (PCA) method. PCA reduces "the dimensionality of a data set ... while retaining as much as possible of the variation present in the data set" $[54$, p. 1]. See the factor approach to EGDI in [42]. We determined the number of components to retain using eigenvalue greater than 1 (Kaiser rule) and at least $80 \%$ variance explained [54, pp. 111-149].

We name the resulting indicators, which capture the values of the DG value chain's respective stages and transitions: iR, iU, iI, iR2U, and iU2I. In order to preserve comparability in terms of the central tendency and variance, the $\mathrm{z}$-score standardization procedure was applied. So, iR, iU, and iI are the standardized first components of $\mathrm{R}, \mathrm{U}$, and I. The indicators of $\mathrm{R} 2 \mathrm{U}$ and U2I - iR2U and iU2I - are the standardized differences between $\mathrm{iU}$ and $\mathrm{iR}$, and between iI and iU.

Due to the descriptive character of value addition, lacking one established quantification method, we associate value addition with value change between two consecutive stages. As standardized indicators represent these values, they refer to a country's relative position on a scale rather than an external determinant of quality. Given the standardized forms of iR2U and iU2I, if one of them exceeds 1 , we say that the DG value chain produces an R2U (U2I) surplus. If one of them is less than -1 , then it produces R2U (U2I) deficit. Otherwise, the DG value chain is normal. The combination of surplus, deficit, and normal values of R2U and U2I summarizes the state of the chain.

\subsection{Model validity}

The validity relies on the logical interpretation of the literature and two verifying questions.

First, do aggregated data support the constructs behind $\mathrm{R}, \mathrm{U}$, and $\mathrm{I}$ ? The high positive correlations between the original indicators in the respective stages and the positive results of the PCA method application ("in a reflective view, the first principal component is the best solution" [45, p. 106]) at each stage permit us to answer this question affirmatively.

Second, does the order of stages allow us to expect a causal path? Heeks notices that "the causal path from e-Government to outcomes is too indistinct", but also suggests that "it may be worth undertaking some exploratory correlations to see if any patterns emerge" [4, p. 272]. Our model is simplified, thus not meant to explain the values at one stage by those at previous stages. Nonetheless, the high positive correlations between the values of $R$ and $U(0.76)$ and $U$ and I (0.65) support the concept of a logical pattern.

\subsection{Research questions}

We can finally decompose the general research problem into three questions: 1) Which countries are the best and worst in iR2U and iU2I? 2) What are the average values of $i R 2 U$ and iU2I in the geographic and economic groupings? 3) How do the values of iR2U and iU2I correspond to the values of EGDI?

\section{Findings}

Table 4 depicts basic descriptive statistics for the input dataset. Some elements are worth noticing: moderate skewness of HCI (negative), and TI and CC (positive); the platykurtic character of the distributions, especially for OSI and EPI; and GE, VA, and CC not revealing averages equal to 0 and standard deviation to 1 , because they are a subset of the original dataset.

Table 4. Original dataset - descriptive statistics

\begin{tabular}{|r|r|r|r|r|r|}
\hline & Mean & Med. & St. dev. & Skew. & Kurt. \\
\hline HCI & 0.65 & 0.71 & 0.20 & -0.74 & -0.09 \\
\hline TI & 0.36 & 0.31 & 0.25 & 0.52 & -0.82 \\
\hline OSI & 0.46 & 0.46 & 0.27 & 0.10 & -1.10 \\
\hline EPI & 0.47 & 0.49 & 0.27 & 0.05 & -1.07 \\
\hline GE & -0.08 & -0.21 & 0.99 & 0.24 & -0.39 \\
\hline VA & -0.04 & 0.04 & 1.00 & -0.21 & -0.95 \\
\hline CC & -0.08 & -0.25 & 0.99 & 0.61 & -0.31 \\
\hline
\end{tabular}

Using the standard "boxplot" technique [55], we identified just one outlier in the entire dataset - South Sudan with $0.00 \mathrm{HCI}$ in 2014. Considering its marginal impact on further calculations, we retained this case. 
In line with our assumptions, within a single stage, all pairs are strongly and positively correlated. For R, the correlation coefficient between HCI and TI is 0.80 ; for $\mathrm{U}$, the correlation between OSI and EPI is 0.97; for $\mathrm{I}$, the correlation between GE and VA is 0.71 , between $\mathrm{GE}$ and $\mathrm{CC}$, is 0.91, and between VA and CC is 0.78 .

Table 5 presents standard deviations and share of variance for the first components, computed for each stage. In line with our assumptions, each component has an eigenvalue (the square of standard deviation) bigger than one and explains over $80 \%$ of the original variance. Thus, they provide a good summary of the original data. For $\mathrm{R}$ and $\mathrm{U}$, both component loadings are 0.71 . For I, they are: GE 0.58 , VA 0.55 , CC 0.60 .

Table 5. First Principal Components for the stages

\begin{tabular}{|l|c|c|}
\hline Stage & Standard deviation & Share of variance \\
\hline R & 1.34 & 0.90 \\
\hline U & 1.40 & 0.99 \\
\hline I & 1.61 & 0.87 \\
\hline
\end{tabular}

Here are the top and bottom countries considering the values of iR, iU, and iI. Countries with the highest value of $\mathrm{iR}$ are South Korea (1.95), Australia (1.84), and Iceland (1.75), with the lowest are Somalia (-2.42), Niger (-2.09), and Burkina Faso (-1.90). Countries with the highest value of $\mathrm{iU}$ are the United Kingdom (1.99), Australia (1.91), and South Korea (1.82), with the lowest, the Central African Republic (-1.72), Djibouti (-1.69), and Tuvalu (-1.69). Countries with the highest values of iI are Finland (2.18), Norway (2.14), and Switzerland (2.13), with the lowest are South Sudan $(-2.15)$, Somalia (-2.03), and Yemen (-1.96).

Table 6 lists five the most and five the least successful countries in turning DG readiness into DG uptake. The most successful are India (2.92), Ethiopia (2.63), and Morocco (2.43). The least successful are Antigua and Barbuda (-2.68), Palau (-2.66), and Libya $(-2.30)$. Remarkably, half of the ten least successful countries are Small Island Developing States (SIDS).

Table 6. iR2U - 5 top and bottom countries

\begin{tabular}{|l|c|l|c|}
\hline \multicolumn{2}{|c|}{ Top 5 } & \multicolumn{2}{c|}{ Bottom 5 } \\
\hline Country & iR2U & Country & iR2U \\
\hline India & 2.92 & Antigua and Barbuda & -2.68 \\
\hline Ethiopia & 2.63 & Palau & -2.66 \\
\hline Morocco & 2.43 & Libya & -2.30 \\
\hline Bangladesh & 2.41 & Saint Kitts and Nevis & -2.12 \\
\hline Tanzania & 2.24 & Tuvalu & -2.05 \\
\hline
\end{tabular}

Table 7 lists five the most and five the least successful countries in turning DG uptake into DG impact. The most successful are Tuvalu (2.28), Micronesia (2.06), and Palau (2.06); the least are Uzbekistan (-2.27), Mexico (-2.14), and Russia (-1.97).
Remarkably, four out of the five most successful countries in turning DG uptake into DG impact are SIDS. An interesting pattern emerges here: successful governance with little contribution from DG. On the other side, a group of countries like Morocco, Mexico, and China, which all successfully turned DG readiness into uptake, cannot turn DG uptake into impact.

Table 7. iU2I - 5 top and bottom countries

\begin{tabular}{|l|c|l|c|}
\hline \multicolumn{2}{|c|}{ Top 5 } & \multicolumn{2}{c|}{ Bottom 5 } \\
\hline Country & iU2I & Country & iU2I \\
\hline Tuvalu & 2.28 & Uzbekistan & -2.27 \\
\hline Micronesia & 2.06 & Mexico & -2.14 \\
\hline Palau & 2.06 & Russia & -1.97 \\
\hline Switzerland & 1.99 & Bahrain & -1.91 \\
\hline Andorra & 1.88 & Azerbaijan & -1.89 \\
\hline
\end{tabular}

The overall state of the DG value chain comprises: 101 countries produce normal iR2U and iU2I, 17 produce normal iR2U and deficit iU2I, 16 produce normal iR2U and surplus iU2I, 16 produce deficit iR2U and normal iU2I, 14 produce deficit iR2U and surplus iU2I, 12 produce surplus iR2U and normal iU2I, and 15 produce surplus iR2U and deficit iU2I. Statistical construction impacts this distribution.

It is also worth listing the countries where the advantage of iR2U over iU2I (left part of Table 8) or of iU2I over iR2U (right part of Table 8) is exceptionally high. Countries like Morocco or Mexico successfully developed DG but failed in creating good governance. On the other side, SIDS like Palau or Antigua achieve good governance despite low DG uptake.

\section{Table 8. Highest differences between iR2U and iU2I}

\begin{tabular}{|l|c|l|c|}
\hline Country & iR2U-iU2I & Country & iU2I-iR2U \\
\hline Morocco & 4.22 & Palau & 4.71 \\
\hline Mexico & 4.11 & Antigua and Barbuda & 4.43 \\
\hline India & 3.93 & Tuvalu & 4.33 \\
\hline Bangladesh & 3.85 & Saint Kitts and Nevis & 3.85 \\
\hline Ethiopia & 3.70 & Barbados & 3.54 \\
\hline
\end{tabular}

Turning to the regional analysis, Table 9 presents the most and the least successful regions in turning DG readiness into DG uptake using the average values of iR2U for those regions. Southern Asia is the most, and Micronesia and Polynesia are the least successful regions in that respect.

Table 9. iR2U (average) - 5 top and 5 bottom subregions

\begin{tabular}{|l|c|l|c|}
\hline \multicolumn{2}{|c|}{ Top 5 } & \multicolumn{2}{c|}{ Bottom 5 } \\
\hline Region & iR2U & Region & iR2U \\
\hline Southern Asia & 1.02 & Micronesia & -1.35 \\
\hline Sub-Saharan Africa & 0.35 & Polynesia & -1.23 \\
\hline Northern America & 0.34 & Central Asia & -0.52 \\
\hline South-eastern Asia & 0.17 & Western Europe & -0.47 \\
\hline Western Asia & 0.17 & Northern Europe & -0.44 \\
\hline
\end{tabular}


Table 10 captures regional success in turning DG uptake into DG impact. The most successful regions are Micronesia, Polynesia, and Melanesia; the least successful are Central, Western, and Eastern Asia.

Table 10. iU2I (average) - top and bottom 5 subregions

\begin{tabular}{|l|c|l|c|}
\hline \multicolumn{2}{|c|}{ Top 5 } & \multicolumn{2}{c|}{ Bottom 5 } \\
\hline Region & iU2I & Region & iU2I \\
\hline Micronesia & 1.85 & Central Asia & -1.06 \\
\hline Polynesia & 1.54 & Western Asia & -0.82 \\
\hline Melanesia & 0.98 & Eastern Asia & -0.80 \\
\hline Western Europe & 0.84 & Northern Africa & -0.70 \\
\hline Northern Europe & 0.57 & Eastern Europe & -0.50 \\
\hline
\end{tabular}

Concerning the economic analysis, Table 11 depicts the average values of iR2U and iU2I for four income groups. For iR2U, the lower the income, the higher iR2U. As high-income countries have high Rvalue already, this is unsurprising. For iU2I, the lowincome group turns DG uptake into DG impact better than the lower-middle- or upper-middle-income group but worse than the high-income group.

Table 11. IR2U and iU2I (average) for income groups

\begin{tabular}{|l|c|c|}
\hline Income group & $\mathrm{iR} 2 \mathrm{U}$ & $\mathrm{iU} 2 \mathrm{I}$ \\
\hline High & -0.39 & 0.32 \\
\hline Upper-middle & -0.32 & -0.11 \\
\hline Lower-middle & 0.37 & -0.20 \\
\hline Low & 0.63 & -0.03 \\
\hline
\end{tabular}

Finally, consider the relationship with EGDI. The correlation between EGDI (2016) and iR2U or iU2I is negligible - Pearson coefficients are 0.06 and -0.16 , respectively. Thus, EGDI says little about the DG value chain. Given the thresholds in the UN survey $(0.25,0.5,0.75)$, Table 12 depicts the average values of iR2U and iU2I for the four groups. Note that lowEGDI countries turn their low DG readiness into good DG uptake and further into DG impact, while highEGDI countries fail to turn DG uptake into DG impact. The middle-EGDI group is better in turning DG uptake into impact than in turning DG readiness into uptake.

Table 12. iR2U and iU2I (average) for EGDI groups

\begin{tabular}{|l|c|c|}
\hline EGDI group & iR2U & iU2I \\
\hline Very High & -0.09 & 0.15 \\
\hline High & 0.07 & -0.43 \\
\hline Middle & -0.16 & 0.23 \\
\hline Low & 0.28 & 0.29 \\
\hline
\end{tabular}

\section{Discussion}

The highlight of our approach to assessing value addition through DG is to examine differences between stages in the DG value chain. While the chain is variably described in the literature, we managed to utilize the existing benchmarks and propose a simple measurement model that follows the logical path from DG readiness to DG uptake to DG impact. Our model offers a viable path to a comprehensive and diagnostically useful scheme of DG assessment.

The research results reveal several facts that are hidden from traditional indicators. First, the patterns of DG value addition strongly vary. A group of countries like China, Mexico, or Morocco can turn DG readiness into DG uptake and fail to turn DG uptake into DG impact. A group of countries, including Palau, Antigua, or Barbuda, fail to build DG uptake, despite DG readiness but succeed in producing DG impact. Second, the findings highlight diversity in the DG value chains within regional and economic groups. Third, the results confirm doubts about the diagnostic value of the EGDI Survey. Effectively, EDGI is mute on whether DG is developed optimally or contributes to improvements in public governance.

As part of this study, we learned that evaluating countries' DG performance through the value-based approach provides useful insights into how DG works. Existing data is imperfect, but additional indicators and intelligent rearrangement may reveal problems raised in literature as peculiarities of the existing benchmarks.

This work may be beneficial to various groups of DG stakeholders. Researchers may refer to the DG value chain model as an alternative way of analyzing and explaining digital transformation mechanisms. Benchmark designers could find ideas on different ways of building their instruments. Policy-makers could learn whether and why certain countries manage to benefit from DG while others fail to do so and find analogies and useful lessons for their own countries.

\section{Conclusions}

In this study, we examined the countries' DG performance from a different perspective than existing benchmarks. Instead of capturing the state of selected DG mechanisms, we captured how DG creates value holistically. To this end, we referred to the concept of the value chain and redesigned the existing schema of DG measurement to reflect the logic of this chain. The results revealed the most and the least successful countries in realizing the DG value chain, produced insights about the performance of such chains within geographic and economic groups, and compared such performance with the UN Survey findings.

This research has some limitations. The first is the simplified nature of the DG value chain in our model, which balances theory-based conceptualizations and what existing benchmarking instruments have to offer. The second is quantifying DG stages and transitions 
relative to the countries' positions, not relative to external DG guidelines. Third, as the results refer to a particular period - 2014, 2016, and 2018 - they do not convey a sustained tendency. Fourth, while we examined the DG value chain performance against a list of factors, this list is not exhaustive.

In the future, we plan to develop this model into a more comprehensive and reusable framework. We also plan to explore the literature and harness additional statistical techniques to build a useful toolset to help design and analyze DG value chains.

\section{References}

[1] E. G. Boring, "Intelligence as the Tests Test It," New Repub., no. 36, pp. 35-37, 1923.

[2] A. D. Paoli and S. Leone, "Challenging Conceptual and Empirical Definition of e-Government toward Effective e-Governance," Int. J. Soc. Sci. Humanit., vol. 5, no. 2, pp. 186-194, 2015.

[3] P. Panagiotopoulos, B. Klievink, and A. Cordella, "Public value creation in digital government (authors' version)," Gov. Inf. Q., vol. 36, no. 4, 2019.

[4] R. Heeks, "Benchmarking e-Government: Improving the national and international measurement, evaluation and comparison of e-Government," in Evaluating Information Systems. Public and Private Sector, vol. 53, no. 9, Z. Irani and P. Love, Eds. London, New York: Routledge, 2008, pp. 257-301.

[5] E. Barcevičius et al., "Exploring Digital Government transformation in the EU - Analysis of the state of the art and review of literature," Luxembourg, 2019.

[6] F. Bannister, "The curse of the benchmark: An assessment of the validity and value of e-government comparisons," Int. Rev. Adm. Sci., vol. 73, no. 2, pp. 171-188, 2007.

[7] World Bank, “WGI 2019 Interactive," 2019. [Online]. Available:

http://info.worldbank.org/governance/wgi/Home/Docu ments. [Accessed: 01-May-2020].

[8] Cambridge Dictionary, "PROCESS | definition in the Cambridge English Dictionary," 2020. [Online]. Available:

https://dictionary.cambridge.org/us/dictionary/english/p rocess. [Accessed: 29-Jun-2020].

[9] B. W. Wirtz and P. Daiser, E-Government: Strategy Process Instruments. Textbook for the Digital Society. 2nd edition, Speyer. Speyer, 2017.

[10] G. Hu, W. Pan, M. Lu, and J. Wang, "The widely shared definition of e-Government," Electron. Libr., vol. 27, no. 6, pp. 968-985, 2009.

[11] N. Bindu, C. P. Sankar, and K. S. Kumar, "From conventional governance to e-democracy: Tracing the evolution of e-governance research trends using network analysis tools," Gov. Inf. Q., vol. 36, no. 3, pp. 385-399, 2019.

[12] D. D. Navarra and T. Cornford, "The State and
Democracy After New Public Management: Exploring Alternative Models of E-Governance," Inf. Soc., vol. 28, no. 1, pp. 37-45, 2012.

[13] F. Bannister and R. Connolly, "New Problem for Old? Defining e-Governance," in Proceedings of the 44th Hawaii International Conference on System Sciences 2011, 2011, pp. 1-10.

[14] M. Janssen and W. S. Shu, Transformational government: basics and key issues., vol. 351. 2008.

[15] V. Weerakkody and G. Dhillon, "Moving from egovernment T-government: A study of process reengineering challenges in a UK local authority context," in International Journal of Electronic Government Research, 2008, vol. 4, no. 4, pp. 1-16.

[16] D. Potnis and T. A. Pardo, "Evolution of readiness indicators," in Proceedings of the 2nd International Conference on Theory and Practice of Electronic Governance, ICEGOV 2008, Cairo, Egypt, December 1-4, 2008, 2009, p. 417.

[17] United Nations, "E-Government Survey 2018: Gearing E-Government to support transformation towards sustainable and resilient societies," New York, 2018.

[18] A. Ayanso, D. Chatterjee, and D. I. Cho, "EGovernment readiness index: A methodology and analysis," Gov. Inf. Q., vol. 28, no. 4, pp. 522-532, 2011.

[19] C. Renteria, J. Ramon Gil-Garcia, and T. A. Pardo, "Toward an enabler-based digital government maturity framework: A preliminary proposal based on theories of change," ACM Int. Conf. Proceeding Ser., vol. Part F1481, no. August, pp. 408-417, 2019.

[20] A. Fath-Allah, L. Cheikhi, R. Al-Quantish, and A. Idri, "E-Government Maturity Models: A Comparative Study," Int. J. Softw. Eng. Appl., vol. 5, no. 3, pp. 7191, 2014.

[21] T. Janowski, "Digital government evolution: From transformation to contextualization," Gov. Inf. Q., vol. 32, no. 3, pp. 221-236, 2015.

[22] K. Layne and J. Lee, "Developing fully functional Egovernment: A four stage model," Government Information Quarterly, vol. 18, no. 2. pp. 122-136, 2001.

[23] U. Bititci and D. Muir, "Business process definition: A bottom-up approach,” Int. J. Oper. Prod. Manag., vol. 17, no. 4, pp. 365-374, Apr. 1997.

[24] NECS and NHS, "Logic Models - A Practical Guide," pp. 1-10, 2016.

[25] M. E. Porter, Competitive Advantage. Creating and Sustaining Superior Performance. New York: The Free Press, 1985.

[26] J. McGee, "Value Chain," in Wiley Encyclopedia of Management 3rd edition, vol. 12, no. January 2014, J. McGee and T. Sammut-Bonnici, Eds. John Wiley \& Sons, Ltd, 2015.

[27] T. B. Jørgensen and B. Bozeman, "Public values: An inventory," Adm. Soc., vol. 39, no. 3, pp. 354-381, 2007.

[28] J. D. Twizeyimana and A. Andersson, "The public 
value of E-Government - A literature review," Gov. Inf. Q., vol. 36, no. 2, pp. 167-178, 2019.

[29] A. Ojo, Z. Dzhusupova, and T. Janowski, "Measuring Electronic Governance - State of Practice", eMacao report 193, 2012.

[30] A. Wassenaar, "E- Governmental Value Chain Models," in Proceedings 11th International Workshop on Database and Expert Systems Applications, 2000, pp. 289-293.

[31] R. Heeks and M. Alemayehu, "Impact Assessment of ICT-for-Development Projects: A Compendium of Approaches," Development Informatics Group. Institute for Development Policy and Management, Manchester, 2009.

[32] R. Heeks and S. Krishna, "ICTs and hope for development: A theoretical framework," Electron. J. Inf. Syst. Dev. Ctries., vol. 77, no. 1, pp. 1-19, 2016.

[33] I. Mergel, N. Edelmann, and N. Haug, "Defining digital transformation: Results from expert interviews," Gov. Inf. Q., vol. 36, no. 4, p. 101385, 2019.

[34] D. K. Basyal, N. Poudyal, and J. W. Seo, "Does Egovernment reduce corruption? Evidence from a heterogeneous panel data model," Transform. Gov. People, Process Policy, vol. 12, no. 2, pp. 134-154, 2018.

[35] J. Wallis and F. Zhao, "e-Government Development and Government Effectiveness: A Reciprocal Relationship," Int. J. Public Adm., vol. 41, no. 7, pp. 479-491, 2018.

[36] S. Stier, "Political determinants of e-government performance revisited: Comparing democracies and autocracies," Gov. Inf. Q., vol. 32, no. 3, pp. 270-278, 2015.

[37] J. Durkiewicz and T. Janowski, "Towards Synthetic and Balanced Digital Government Benchmarking," Proc. 53rd Hawaii Int. Conf. Syst. Sci., pp. 2123-2132, 2020.

[38] J. Stragier, P. Verdegem, and G. Verleye, "How is egovernment progressing? A data driven approach to egovernment monitoring," J. Univers. Comput. Sci., vol. 16, no. 8, pp. 1075-1088, 2010.

[39] A. Savoldelli, G. Misuraca, and C. Codagnone, "Measuring the Public Value of E-Government: The eGEP2.0 model," Electron. J. e-Government, vol. 11, no. 1, pp. 373-388, 2013.

[40] R. Máchová and M. Lněnička, "Reframing Egovernment development indices with respect to new trends in ICT," Rev. Econ. Perspect., vol. 15, no. 4, pp. 383-411, 2015.

[41] D. Tinholt, "e-Government Benchmarks Assessment," 2017.

[42] A. Whitmore, "A statistical analysis of the construction of the United Nations E-Government Development Index," Gov. Inf. Q., vol. 29, no. 1, pp. 68-75, 2012.

[43] S. Mukamurenzi, Å. Grönlund, and S. M. Islam, "Evaluating eGovernment Evaluation : Trend and Issues," Electron. Gov. Electron. Particip. Jt. Proc. Ongoing Res. Proj. IFIP WG 8.5 EGOV ePart 2012, vol. 23, pp. 344-351, 2016.

[44] M. Hussein, "a Preliminary Work on Investigating United Nations'S E-Government Criteria in Middle East Countries," Int. J. Ebus. eGovernment Stud., vol. 9, no. 2, pp. 51-71, 2017.

[45] M. Mazziotta and A. Pareto, "On the Construction of Composite Indices by Principal Component Analysis," Rivisita Ital. di Econ. Demogr. e Stat., vol. LXX, no. 1, pp. 103-109, 2016.

[46] Å. Grönlund, "Connecting eGovernment to real government - The failure of the UN eParticipation index," Lect. Notes Comput. Sci. (including Subser. Lect. Notes Artif. Intell. Lect. Notes Bioinformatics), vol. 6846 LNCS, pp. 26-37, 2011.

[47] E. Barber, "How to measure the 'value' in value chains," Int. J. Phys. Distrib. Logist. Manag., vol. 38, pp. 685-698, Oct. 2008.

[48] Y. Y1lmaz and U. Bititci, "Performance measurement in the value chain: Manufacturing v. tourism," Int. J. Product. Perform. Manag., vol. 55, pp. 371-389, Jul. 2006.

[49] G. Spirakis, C. Spiraki, and K. Nikolopoulos, "The impact of electronic government on democracy: edemocracy through e-participation," Electron. Gov. an Int. J., vol. 7, no. 1, p. 75, 2010.

[50] United Nations, "UNSD — Methodology,” 2020. [Online]. Available: https://unstats.un.org/unsd/methodology/m49/overview I. [Accessed: 25-Apr-2020].

[51] World Bank, "World Bank Country and Lending Groups - World Bank Data Help Desk,” 2020. [Online]. Available: https://datahelpdesk.worldbank.org/knowledgebase/arti cles/906519-world-bank-country-and-lending-groups. [Accessed: 23-Jul-2019].

[52] United Nations, "Data Center," 2020. [Online]. Available: https://publicadministration.un.org/egovkb/en-us/DataCenter. [Accessed: 04-Jul-2020].

[53] World Bank, "Worldwide Governance Indicators (WGI) | Data Catalog,” 2020. [Online]. Available: https://datacatalog.worldbank.org/dataset/worldwidegovernance-indicators. [Accessed: 04-Jul-2020].

[54] I. T. Jolliffe, Principal Component Analysis. Second Edition. New York, Berlin, Heidelberg: SpringerVerlag, 2002.

[55] NIST/SEMATECH, "7.1.6. What are outliers in the data?" Engineering Statistics Handbook, 2020. [Online]. Available: https://www.itl.nist.gov/div898/handbook/prc/section1/ prc16.htm. [Accessed: 06-Jul-2020]. 